\title{
Original Research \\ Results of chart reviews conducted to evaluate primary care patients seen by second and third year family medicine residents for potential adverse polypharmacy
}

Linda F. CHANG, May N. LUTFIYYA, Isaac CHA, Ehab EL-KHABIRY.

\begin{abstract}
${ }^{*}$
Objective: To determine the prescribing patterns of family medicine residents for patients aged more than 60 years with 2 or more chronic diseases and seen at least twice in a 12 month timeframe. Methods: This is a descriptive analysis which was based on chart reviews. The setting was the University of Illinois-Rockford Family Practice Residency. Patients aged 60 years with 2 or more chronic diseases who were seen at least twice by second and third year residents.

Results: Findings from this chart review include: $28.8 \%$ of the prescribed medications were not effective for the documented condition, $26.3 \%$ of the prescribed doses were incorrect, and $44.5 \%$ of the drugs prescribed were not the least expensive alternative.

Discussion: This preliminary study suggests a need for a focused intervention with family medicine residents regarding inappropriate polypharmacy issues with older patients.
\end{abstract}

Keywords: Polypharmacy. Aged. Drug Utilization Review. United States.

\begin{abstract}
RESUMEN
Objetivo: Determinar los modelos de prescripción de los médicos de familia para pacientes de más de 60 años con 2 o más enfermedades crónicas y vistos al menos 2 veces en los últimos 12 meses. Métodos: Análisis descriptivo basado en revisión del os historiales. El emplazamiento fue la Residencia de Medicina de Familia de Rockford del a Universidad de Illinois. Los pacientes de más de 60 años con 2 o más enfermedades crónicas que fueron vistos al menos dos veces por los residentes de segundo y tercer año.

Resultados: Los hallazgos de los historiales incluyen: $28,8 \%$ de medicamentos que no eran efectivos para la condición documentada, $26,3 \%$ de dosis prescritas eran incorrectas, y 44,5\% de los medicamentos prescritos no eran más baratos que sus alternativas.

Discusión: Este estudio preeliminar sugiere que es necesaria una intervención sobre los residentes de medicina de familia sobre los problemas de polimedicación inapropiada en ancianos.
\end{abstract}

Palabras clave: Polimedicación. Ancianos. Revisión del a medicación. Estados Unidos.

\section{(English)}

\section{INTRODUCTION}

According to the National Center for Health Statistics, life expectancy in the US has recently reached an all-time high of nearly 77 years with life expectancy for women 79.5 years and at 74.1 years for men. ${ }^{1}$ In the last US Census (2000), 281.4 million people were counted as living in the United States and of this number, 35.0 million, or 12 percent, were aged 65 and over. ${ }^{2}$ Hence, approximately one in every eight person residing in the U.S. is 65 years of age or older with women outnumbering men in this age group.

Not surprisingly, this increase in lifespan has had and will continue to have an ongoing impact on dramatically increasing the proportion of seniors, with the 85 and over making up the fastest growing segment of the US population. In 1996, the baby boomers (those born between 1946 and 1964) began to turn 50 , and will in-turn begin turning 60 in the year $2006 .^{2}$ By some estimates, about 22 million 
baby boomers will still be living in 2030 , when all will be past age 65. As the life expectancy of Americans has increased, there has been a corresponding demographic transition from high fertility and high mortality rates to low fertility and delayed mortality and an epidemiologic transition in the leading causes of morbidity and mortality, from infectious disease and acute illness to chronic disease and degenerative illness. ${ }^{1}$

With increased age, people develop multiple comorbidities that are often also chronic in nature. Appropriate treatment of these multiple chronic illnesses often necessitates the use of multiple medications as an important means of staying healthy, and controlling chronic health problems. However, the use of multiple medications can be a two-edged sword that can contribute to one of the leading cause of morbidity and mortality. McGavock calls this polypharmacy induced disease a pandemic. $^{3}$ This pandemic is particularly problematic among the elderly who are especially vulnerable to adverse drug events due to both polypharmacy and to various biological changes from aging and chronic diseases.

Researchers have estimated that the increase in the number of medications is 0.4 drugs per 10 years of age and that two-thirds of medication users over the age of 70 take two to four medications, and one-fifth take five or more drugs. ${ }^{4,5}$ Co-morbidity and polypharmacy, hence, provide new challenges to the delivery of health care services that have traditionally focused on individual diseases with little substantial collaboration between primary care physicians and other health care specialists such as pharmacists.

With an increase in the population of older Americans and the corresponding shifts in the leading causes of death, additional medical training has become essential. In particular, medical training at the residency level needs to be expanded to include additional training on the various complex issues related to polypharmacy in the elderly. This notion is not lost on pharmacists currently working as faculty in Family Medicine Departments. In 2005, the Society of Teachers of Family Medicine Group on Pharmacotherapy developed suggested guidelines for a pharmacotherapy curriculum in family medicine residency programs. ${ }^{6}$ These guidelines were developed to both address the need for additional pharmacotherapy training for family medicine residents as well as to meet the new ACGME requirements for residency training.

As several authors have noted the role of the pharmacist has evolved over the past several decades. $^{7-9}$ At the turn of the 20th century, pharmacists primarily had a distribution role that was limited to compounding, packaging and dispensing medications. Occasionally, the pharmacist's role also encompassed the work of providing advice about over-the-counter drugs. This very limited scope of practice expanded as the pharmaceutical industry took over much of the function of preparing medications allowing more time for the pharmacists to provide cognitive services. As a result of these changes in the market forces, along with extensive changes in the US pharmacy school curriculum culminating in graduating pharmacists with clinical training at the doctoral level, the pharmacists' role has evolved to the role of a pharmaceutical care specialist which encompasses not only providing advice to patients and physicians about the appropriate use of medications but also providing health promotion advice.

As a result of changes in their professional practice, clinical pharmacists in the US and Europe now contribute significantly to enhancing the physician's knowledge about drugs. This contribution occurs in multiple venues including: training medical students, training residents and working along side physicians in ambulatory and hospital settings. Working in these venues, the clinical pharmacists not only help to reduce the quantity and cost of drugs by medication reviews, but they also perform specific clinical activities, such as the management of anticoagulation clinics and regular check-up visits to patients with hypertension or diabetes mellitus. Pharmaceutical care now also involves identifying, resolving and preventing drug-related problems (e.g. adverse affects, administration problems, and etc.).

The aging US population has intensified the need for the pharmacist's expertise in medication management. With age people develop multiple comorbidities that are often also chronic in nature and when these comorbidities are treated pharmacotherapeutically, possible adverse affects from polypharmacy becomes a challenge. While polypharmacy has many definitions, we prefer one shared by Montamat and Cusack and Hanlon, Schmader, and Ruby. ${ }^{10,11}$ This definition, encompassing the complexity of polypharmacy, is: the prescription, administration or use of more medications than are clinically indicated in a given patient. This definition recognizes the fact that only one unnecessary medication can lead to adverse events that could have been avoided, and equally excludes an arbitrary minimum number of medications.

In a review of published polypharmacy intervention studies focused on older patients, it was noted that the outcome most often reported was a reduction in costs that occurs in parallel with a reduction in the number of drugs taken by the patients. ${ }^{7}$ While this outcome, they note, was important from an economic point of view, it was not an outcome focused on patient well-being.

While the impact for medication-related problems in the elderly is both common and serious, there is a large body of literature that has shown that these problems are largely preventable through better understanding of appropriate medication use in the older population. ${ }^{3}$ The importance and urgency of providing adequate training in geriatric pharmacotherapy to frontline physicians has provided the impetus for this pilot study.

This research project was conducted as a pilot study focused on examining whether or not family medicine residents practiced appropriate 
polypharmacy with older patients. The purpose of conducting this pilot study was to determine if an intervention aimed at reducing adverse polypharmacy with older patients was necessary at a university Family Medicine residency program. The question guiding this preliminary and exploratory work was: What is the prescribing pattern of second and third family medicine residents for patients 60 years of age and older with at least two chronic diseases and seen at least twice in a 12 month timeframe?

\section{METHODS}

The analysis undertaken in this pilot study was descriptive in nature. In June and July 2004 chart reviews were conducted on all patients aged over sixty years with at least two documented chronic diseases and seen at least twice by second and third year residents in a family medicine outpatient clinic between 1 January 2003 and 31 December 2003. Because this project was aimed at quality control it was deemed IRB exempt.

The chart review focused on the following ten items:

- number of medications

- drug duplication

- clinically significant drug-disease interactions

- clinically significant drug-drug interactions

- medication indications

- drug side effects

- medication effective for condition

- appropriate dosing and directions

- drug expense in comparison to alternative

- practicality of drug use directions.

Once selected as meeting the inclusion criteria, the patient charts were abstracted and data entered into a customized database constructed for this study. In the abstraction process, progress notes were by and large ignored as a data source in favour of information garnered from the chart's problem list, medication list and necessary lab results. The residency's PharmD faculty member abstracted all of the pertinent data from the patient charts and once finished removed personal identifiers from the database leaving a case number for non-personal case identification.

Decisions regarding medication indications and medication effectiveness for condition were determined using the most recent standards of care and available evidence-based medicine (i.e. American Diabetes Association, The Seventh Report of the Joint National Committee on Prevention, Detection, Evaluation, and Treatment of High Blood Pressure, etc.). These same decision criteria were used for appropriate dosing and directions. Drug expense in comparison to alternative entailed determining if there was a generic drug available when a brand name drug was prescribed.

Statistical Package for Social Scientists version 12.0 (SPSS 12.0) was used for all data analysis.

\section{RESULTS}

Table 1 presents the descriptive data of patient characteristics for those selected as meeting the inclusion criteria for the study. In all, seventeen residents had patient charts reviewed for inclusion in this study with each resident having at least one patient that met the inclusion criteria for the study. The residents saw anywhere from 1 to 14 patients with 7 patients being seen by more than one resident. In total 64 patient charts met the inclusion criteria and were examined for data abstraction. The age of the patients whose charts met the inclusion criteria ranged from 60 to 89 years with a mean age of 71.5 years. A total of 54 different diagnoses were yielded from the data with a range of 2-7 diagnoses and a mean of 3 diagnoses per patient.

\begin{tabular}{|l|c|}
\hline $\begin{array}{l}\text { Table 1. Description of Patient Characteristics Meeting Inclusion Criteria } \\
\text { For Study }\end{array}$ \\
\hline Number of Patients Meeting Inclusion Criteria & 64 \\
\hline Number of Residents Seeing Patients & 17 \\
\hline Number of Patients Seen By More than 1 Resident & 7 \\
\hline Age Range of Patients Meeting Inclusion Criteria & $60-89$ years \\
\hline Mean Age of Patients Meeting Inclusion Criteria & 71.5 years \\
\hline Number of Different Diagnoses Abstracted from Charts & 54 \\
\hline Range of Number of Different Diagnoses Per Patient & $2-7$ \\
\hline Mean Number of Diagnoses Per Patient & 3 \\
\hline
\end{tabular}

\begin{tabular}{|c|c|}
\hline Number of Medications & 107 Different Drugs Prescribed \\
\hline Number of Prescriptions & 274 \\
\hline Range of Number of Different Drugs Prescribed Per Patient & $2-9$ \\
\hline Mean Number of Drugs Prescribed Per Patient & 4 \\
\hline Unnecessary Drug Duplication & $17.2 \%$ \\
\hline Clinically Significant Drug-Disease or Drug-Drug Interactions & $14.0 \%$ \\
\hline $\begin{array}{l}\text { Medication Indications (no medical condition for a specific prescribed drug had } \\
\text { been documented) }\end{array}$ & $13.5 \%$ \\
\hline Duration of Drug Therapy Incorrect & $29 \%$ \\
\hline Medication Not Effective For Condition & $28.8 \%$ \\
\hline Appropriate Dosing (prescribed dose incorrect) & $26.3 \%$ \\
\hline Drug Expense In Comparison To Alternative & $44.5 \%$ \\
\hline
\end{tabular}


The chart review yielded that 274 prescriptions had been written for 107 different drugs. The range of drugs prescribed per patient was from 2 to 9 drugs with a mean of 4 drugs prescribed per patient.

The relevant findings from this chart review are presented in table 2 and include the following:

- In $17.2 \%$ of the instances the unnecessary duplication of drugs was detected.

- In $14.0 \%$ of the instances either a drug-drug or drug-disease interaction was detected.

- In $13.5 \%$ of the instances, no medical condition for a specific prescribed drug had been documented.

- In $28.8 \%$ of the instances the prescribed medication was not effective for the documented condition.

- In $26.3 \%$ of the instances the prescribed dose was incorrect.

- In $29 \%$ of the instances the duration of the drug therapy was incorrect.

- In $44.5 \%$ of the instances the drug prescribed was not the least expensive alternative.

\section{DISCUSSION}

While these results are based on the analysis of abstracted charts from one family medicine residency program, there is no reason to believe that other family medicine residency programs do not face these same issues with polypharmacy and elderly patients with multiple chronic diseases. This preliminary study suggests a need for a focused intervention with family medicine residents regarding polypharmacy issues with older patients.

Based on the results of this preliminary analysis, this intervention needs to focus on: the unnecessary duplication of drugs, drug-drug and drug-disease interactions, ensuring documented medical conditions for each specific prescribed drug, prescribing medication effective for the documented condition, correct dosing and duration of drug therapy, and finally prescribing the least expensive alternative whenever possible.

The intervention could easily be incorporated into the structured fabric of most family medicine residency curricula and should consist of at least four distinct, one-hour noon lectures, taking place once every three months. The topics of the lectures should focus on the following topics:

- Lecture One: General Pharmacokinetic and Pharmacodynamic changes in the elderly or as one ages

- Lecture Two: Specific disease states and Pharmacotherapy issues

- Lecture Three: Polypharmacy/appropriate use of Pharmacotherapy agents in the elderly

- Lecture Four: Pain management in the elderly

Additionally, twice in each study year, every second and third year resident should schedule and complete a one-on-one review and advisory session with a PharmD faculty member. This person doesn't have to be in the Family Medicine department of residency program, they could be a consultant from another university or hospital department. During this review and advisory session, each resident should review with the PharmD faculty member at least three patient charts meeting the following criteria:

- Patients age over sixty years

- Patient has at least two documented chronic diseases

- Patient seen at least twice in the preceding 12 months

\section{References}

1. Public health and aging: Trends in aging—United States and worldwide. MMWR Morb Mortal Wkly Rep 2003;52(6):1016 .

2. Kinsella K, Velkoff V. US Census bureau. An aging world: 2001. US Government Printing Office, 2001: series P95/01-1.

3. McGavock H. Prescription-related illness-a scandalous pandemic. J Eval Clin Pract. 2004;10(4):491-7..

4. Thomas HF, Sweetnam PM, Janchawee B, Luscombe DK. Polypharmacy among older men in South Wales. Eur J Clin Pharmacol. 1999;55(5):411-5.

5. Bjerrum L, Sogaard J, Hallas J, Kragstrup J. Polypharmacy: correlations with sex, age and drug regimen. A prescription database study. Eur J Clin Pharmacol. 1998;54(3):197-202.

6. Bazaldua O, Ables AZ, Dickerson LM, Hansen L, Harris I, Hoehns J, Jackson E, Kraus C, Mayville H, Saseen JJ; Society of Teachers of Family Medicine Group on Pharmacotherapy. Suggested guidelines for pharmacotherapy curricula in family medicine residency training: recommendations from the Society of Teachers of Family Medicine Group on Pharmacotherapy. Fam Med 2005;37(2):99-104.

7. Rollason V, Vogt N. Reduction of polypharmacy in the elderly: a systematic review of the role of the pharmacist. Drugs Aging. 2003;20(11):817-832.

8. Keely JL; American College of Physicians-American Society of Internal Medicine. Pharmacist scope of practice. Ann Intern Med 2002;136(1):79-85.

9. Hepler CD, Strand LM. Opportunities and responsibilities in pharmaceutical care. Am J Hosp Pharm 1990;47(3):533-43

10. Montamat SC, Cusack B. Overcoming problems with polypharmacy and drug misuse in the elderly. Clin Geriatr Med. 1992;8(1):143-58.

11. Hanlon JT, Schmader KE, Ruby CM, Weinberger M. Suboptimal prescribing in older inpatients and outpatients. J Am Geriatr Soc. 2001;49(2):200-9. 